\title{
The concept of sustainable architecture and urbanization in Dakhla and Kharga Oases in Egypt
}

\author{
M. Tawfik \\ Department of Architecture, Higher Institute of Engineering, \\ El-Shorouk Academy, Egypt
}

\begin{abstract}
The role of the research resides in stressing the notion of sustainability in overcoming the development problems in desert cities, as represented in the oases cities (Dakhla and Kharga), through catalyzing the role of such cities and discovering the sources needed for development and how far could such resources be useful. The research evaluates the traditional architecture and urban patterns existing in Dakhla and Kharga Oases and how interactive they are with the surrounding environment and how the environment affects such patterns in return. Moreover, the research aims to highlight how the traditional architecture and urbanization patterns are constrained by the general principals of sustainability in desert areas with a possibility of pinpointing and deducing some desert architectural and urbanization patterns that concord with the environmental features of the oases.

Keywords: sustainability, Dakhla Oasis, Kharga Oasis, Egyptian deserts, sustained architectural design, traditional architecture.
\end{abstract}

\section{Introduction}

Since the beginning of time, the traditional architecture and urbanization patterns worldwide have constituted the notion of sustainability through the simultaneous concordance with the environment by the ultimate use of the natural resources through a framework of developed experience of life long processes of trial and error. Hence, it is of ultimate necessity to study the patterns and designs of the architectural and urbanization patterns of the Egyptian oases and to highlight 
their positive sides to be able to elaborate on the extent to which such architectural and urbanization principles and patterns are applied. Moreover, it is of prime importance to explain how far the patterns and designs concord with the surrounding natural environment in light of the fact that such architectural patterns are considered to be very traditional. However, such traditional patterns were able to handle the surrounding environment through many centuries and have produced solutions for architectural and urbanization related problems. Additionally, the focus of such analysis is to reach conclusions related to the principles and guidelines that govern the process of how the environment controls the future planning processes of the urban complexes in such oases.

\section{Introducing the location of Kharga and Dakhla}

\subsection{Kharga Oasis}

The Kharga Depression is located between the two latitudes 24-26 north and between the two long thuds 30-31 East and is located about 150-200 kilometers to the west of the Nile corresponding to the Aswan-Quena region. The Egyptian Depressions are considered the longest with 160 kilometers in terms of length, while they reach about $80 \mathrm{~km}$ in width. The Depression is located below the surrounding hill level by about 350-400 meters.

\subsection{Dakhla Oasis}

The Dakhla Depression is smaller in size than the Kharga one as it is $150 \mathrm{~km}$ in length and $54 \mathrm{kms}$ in width at its widest points, $28 \mathrm{kms}$ in its average distant points and is $18 \mathrm{kms}$ in its narrowest areas with a total area of 400 square kms. As for the agricultural oasis, which is the beneficial part, it is only 420 square $\mathrm{km}$ or 100,000 acres. On the regional scale, the land level of Dakhla oasis is higher than that of Kharga oasis 1 by at least 100 meters as the lowest point in it is not less than 100 meters above sea level and it increases up to reach 150 meters (Afifi [1]).

\section{The climate in Dakhla and Kharga Oases}

The Western Desert is distinct for its dry climate where rain is very rare to scarce with temperature that can reach $50^{\circ} \mathrm{C}$ during the day time and $32^{\circ} \mathrm{C}$ at night in summer, while during Winter time, it's around $12-13^{\circ} \mathrm{C}$ during day time and can drop to zero- $5^{\circ} \mathrm{C}$ at night. During the summer, the humidity level is very low during June and July reaching $28 \%$, as for winter time, the humidity levels rise to $53 \%[2]$. 


\section{Analyzing and evaluating how the elements of the architectural design in Dakhla and Kharga Oases concord with the principles of sustainability}

\subsection{Conserving energy}

Diesel generators feed Dakhla and Kharga Oases and neighboring villages with electricity. Those generators are not connected to the unified network of the rest of the country. The number of transformers in the oasis reaches 42 transformers; and the transformers work at a 50\% capacity. There are no other electricity sources in the Oasis. The Egyptian Electricity Institution plans to provide two power stations. Mineral water springs are found all over the oases [1].

\subsection{Adaptation to climate}

Various architectural therapies and factors were used to adapt to climate for example; the architect ensures securing the comfortable temperature inside the buildings in the oases through using some factors and architectural solutions that will be illustrated concerning its functioning systems. Some of the most important factors are listed as follows:

- The courtyard: during night, the courtyard releases amounts of solar energy that was saved all day long in its walls and floor to the atmosphere again and at the same time it stores the cool air in it to cool the place during the next day (Waziri [3]).

The courtyard differs during the day as it gets exposed to sun rays as the builders working in the desert oases made the utmost use of the difference in temperature degrees to maintain good air circulation in the buildings. These buildings were constructed around the courtyard through which the air flows swiftly because the light weighted hot air rises up to the atmosphere from the open courtyard thus, allowing cool air to flow inside the rooms replacing the hot air (Al Badawe [4]).

The connection between the upper and lower courtyard by means of the staircase well helps creating air currents that assist in cooling the house internal temperature (Alwakel [5]).
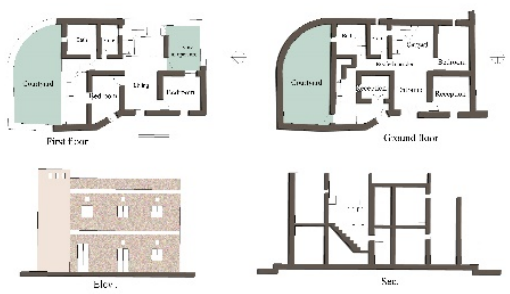

Figure 1: The plans and sections of multi floor building in an oasis. 

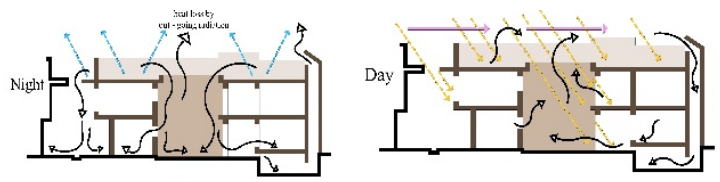

Figure 2: The courtyard and its effect on the air flow inside the rooms (Tntosh [6]).

- Wind towers: the wind towers: are considered one of the most distinctive features of the buildings in the oases. Wind towers are defined as openings entrances that ventilate the buildings by letting the air flow through the entrance and exit through the openings. In case the air flow gets trapped in a room that has no exit openings, it will be filled with still and stuffy air, thus the courtyard is used, in addition to the air coolers, to complete the circle of the air flow inside the internal courtyards (Khairuddin [7]).

- Windows and openings: the small size and number of openings overlooking the building's facades, in addition to the larger number of the openings overlooking the courtyard, help create air flow and wind between the outside and inside, passing through all the rooms inside the building.

- Iwan: Iwan is a roofed hall with only three walls and a totally open fourth side overlooking the courtyard. It might also be preceded by a porch and possibly connected to other halls and rooms depending on the nature of the building.

- Shukhsheekha: Shukhsheekha is used to cover the main halls, provide ventilation and indirect lighting to the hall. Moreover, it works in collaboration with the air coolers to cool the hot air by drawing the hot air to the top part of the room.

- Walls thickness: the huge wall thickness, which could reach 80-100 cm, causes a time lag for the heat to penetrate the interior of the room, hence maintaining the cool temperature during day time, while having a warm temperature by night time. This system is very useful during winter time, especially with the large variation of temperatures, with hot temperature during day and cold temperature at night [7].

- Roof edges: the roof edges could reach 1.5 meters; surround the roofs casting their shadows on the backyard and other house parts. Additionally, there are other shaded areas with palm leaves creating cool and shaded areas for sleeping in open air on top of such roofs and in the courtyards.

- Roofs: domed roofs and vaults are always shaded, except for noon time, thus, increasing the air speed passing through such roofs help in decreasing their temperature.

\subsection{Minimizing new resources}

The residents of the Dakhla and Kharga Oases are keen on using the local construction materials that are available within the local context, especially if they are highly qualified in terms of natural thermal insulation in hot climate. 
Below is a list of the most important construction materials and methods applied by local residents:

Clay bricks: the inside walls of the buildings are built using clay bricks which are based upon walls built by sand stones to protect them. The process of making (casting) the clay brick constitutes of making a soft mixture made out of clay mixed with salt based soil and wheat chaff. The mixture is blended using water and constant stirring with the axe. Then, the mixture is cast in a wooden mud (usually $30 \mathrm{~cm}$ in length, $15 \mathrm{~cm}$ in height and $10 \mathrm{~cm}$ high). Afterwards, the mud is left in the sun to dry for three days, after which they are turned on the other side to ensure complete dryness. A professional builder and some trained assistant workers help him in constructing the buildings (Fathi [8]). During past centuries, many positive solutions were found to counter the negative effects of water on clay based houses. Such solutions depend on the existence of a ceiling to protect the walls from rain and strong underground basis for the buildings to protect them against running water and humidity. Additionally, using paint that is made from tar is useful in protecting the buildings made of clay. The clay bricks are considered the best natural building material that can ensure heat insolation. Only the natural and environmentally bound material is used in building house roofs. Such as the palm branches, which are lined on top of halved palm trees trunks or wooden logs of olive trees trunks that are, in turn covered with clay. Clear catchy aesthetic touches are created through the variation of the patterns in which the palm trees branches are interwoven forming many geometrical shapes. The white lime is used in painting the inside walls, while for painting the outside walls, it is mixed with Iron (III) Oxide (ferric Oxide). Moreover, Karsheefs (high quality rocks made of salt and sand mixed with clay and water that is hardened by the sun heat) are also used in constructing multistory buildings. As for the house doors, they are mainly made out of wood from acacia trees (Elnahass [9]).

\subsection{Compatibility with the cultural and social nature of the desert community}

The prevailing customs and traditions have influenced the architectural designs in many areas in Egyptian oases, since the buildings are constructed to suit the aims and needs required by such communities. Thus, architecture truly and directly expresses the features of the social life. Such reflections could be illustrated as follows (Fakhry [10]):

1. The ground floor openings are small in size and the level of the sitting rooms is higher than the floor levels. Sometimes the openings are too small or sometimes they disappear altogether to ensure the privacy of the residents and protect them from the curious eyes of the pedestrians passing in the street.

2. The house is spacious inwardly as the rooms are designed horizontally overlooking the courtyard directly through large openings and lower living rooms as contrasted to those overlooking the street.

3. Scarcity of squares to link the streets and large public spaces, as the social life there is conservative and restricted to going to the mosque or heading 
home. Such serious and conservative traditions make life more serious in the oases.

4. Roof edges to reach 2.5 meters, thus higher than the human height, to protect everyday life events and home residents from intruding eyes. In addition this would provide privacy in case the residents desire to sleep on top of roofs as accustomed.

5. The residential buildings are co trusted in a flexible design to be horizontally or vertically extended in case the family increases in number.

6. The traditional creative architectural designs have overcome the absence of windows and street openings, by opening windows on top of the wall that overlooks the street. Such windows are formed in architectural and geometrical triangular shapes that decorate the place and let the air flow smoothly.

\section{The principles of sustainable desert urbanism}

The varied natural features of the Egyptian desert have led to a variation in the residents' economic and social patterns of life. The urbanization of the traditional desert cities in the Egyptian deserts could be evaluated through following the basis and criteria of the principles of the sustained desert architecture that could be summed up as follows:

- Concord with the urbanization needs.

- Applying socioeconomic standards to attain quality.

- Maintaining environmental and ecological balance.

- Using natural methods in cooling.

- $\quad$ Establishing a sense of space and visual symmetry.

\section{Analyzing and evaluating how the elements of urban formation in Dakhla and Kharga Oases concord with the principles of sustainability}

\subsection{Concordance with the urbanization needs}

The urbanization needs in any construction are as follows (Bayoumi and Abdullah [11]).

- The degree of inclusion, how far they include the elements of life and development: the existence of the Vast spaces of agricultural land in the oases, the mining resources that are found in complexes in the Eastern Desert, the water resources beside the cities whether they are seas, in the desert coastal cities or underground water wells in the Western Desert complexes are considered the basic factors of life and development in those isolated desert settlements.

- The population densities and the city area: The population densities are relatively suitable for the city area and the urbanized cities in the Egyptian desert complexes. As a result of the small sized cities, any traveling distance does not exceed 400 meters on foot.. The buildings' heights do not exceed 
three stories in most of the cities where the humane view of spaces and nights is still dominant.

- Possibility of multi usage: the residential usages constitute the most prevailing usage for buildings. However, other usages have interfered, such as shops, distilling plants, mills, and others that are considered the service centers of the traditional cities. Moreover, the mosque has occupied the market area.

- Place accessibility and mapping out the network for roads and empty spaces.

- Some of the traditional cities in the Egyptian oases are considered meeting points for many ancient routes that hosted the flows of the ancient trade. The road network follows the framework of the Islamic mapping of cities which is distinct for pyramid like hierarchy, dead end roads or blind alleys and narrow pathways. Some main and semi-main roads could be found in some traditional cities in the oases.

\subsection{Applying socioeconomic standards to attain quality}

The urbanization of the Egyptian cities in the oases could be evaluated, concerning the social and economic aspects, through studying the possibility of creating the sense of social belonging and connection as clarified below [11].

1. The possibility of social blending: the pyramid hierarchy of traditional urban spaces has helped in establishing the social blending and interaction among the people. Those spaces were connected to the social hierarchy of the original inhabitants that consisted of a group of extended families, each family consists of a number of smaller families. Accordingly, the spaces have followed a specific pattern of levels according to the interaction levels and places of interactions. Accordingly, the places are divided into three categories; public places, semipublic places, and private places at the level of residential unity and neighboring rules.

2. Possibility of local independence: the resulting traditional urban and architectural design of residential complexes of the Egyptian oases asserts the effect of the local residents' effect on the formation of their communities and the collective process of houses constructions through the locals' general positive outlook.

3. Possibility of self-containment: the cities in the Egyptian oases are desert communities that possess the basic life elements and full self-containment. Regardless how different their economic circumstances and practices are, where many of them depend on agriculture as a prime economic practice, while others depend on trade due to their location amidst regional axis.

\subsection{Maintaining environmental and ecological balance (Ali [12])}

Using the natural methods for stopping air pollution and dust: the houses are closely interwoven in terms of design and having their facades facing the inner parts of the houses. In addition, opening the houses' entrances on a network of internal paths have played a vital role in constructing back to back walls forming 
an outer fence or wall shielding those urbanized communities. This design has already helped in blocking sand and dust.

Moreover, the narrow covered streets, the internal spaces and the planted courtyards have helped in reducing the rate and size of the sand and dust blowing through such communities.

\subsection{Using natural methods in cooling the temperature}

In order to evaluate the architectural processing methods that were used to cool the atmosphere and lower the temperature In the local houses of the Dakhla and Kharga Oases, a thorough analysis of the elements of architectural design and how they interact with the climate, is of a vital importance

\subsection{Analyzing the elements of the urban formation in Dakhla Oases [5]}

1. The urbanization pattern: through studying such pattern as applied in the cities and villages of the oases, it is found that the traditional closely interwoven pattern is the used pattern in almost all the villages and cities as it results in cooling the effects of the cruel climatic effects and alleviating its effects especially the night temperature, direct sun light, and hot and dusty wind, thus alleviating the heat burden that befalls on the building facades.

2. Movement paths: the streets are distinguished with being narrow and multiple turns. Additionally, the streets are directed in accordance with the clear movement of the Sun. The buildings respect the planned rules that specify the streets width as the city planning layout and handling the movement paths, concerning their width, shape, length, directions and redirections, all such elements constitute the basic system applied to adapt with the environment.

3. The closely interwoven pattern of construction helps shorten the roads' and streets' lengths, in addition to how the broken lines or the $U$ turns help reduce the wind speed.

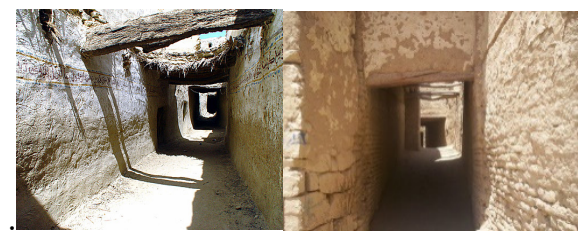

Figure 3: Methods of shading in Oasis Dakhla paths (Alian [13])

\subsection{Establishing a sense of space and visual symmetry (Alzubaidi and Shaheen [14])}

- The clear charisma and atmosphere of the place: each of the patterns that are specific to the traditional cities in the oases has distinctive characteristics that are only peculiar to it concerning the clear urban style, the closely interwoven pattern and the distinctive architectural style. The cities are distinctive for using beads and necklaces, domes and cells, and other distinctive features of the cities. 
- Clear urbanization plan: the traditional oases cities are distinctive for the clear pattern and plan and the pyramid hierarchy of the roads and spaces network. Such hierarchy surfaces as a result of the effect of the social norms and human needs that were reflected in the size of the spaces, buildings and heights. Moreover, the visual alignments in the paths in such old cities have created organic coherence among buildings, thus, creating a sense of spiritual engagement, security and peace among the local residents.

- Functional alignment and visual expression: the architecture of the traditional urbanized cities in the Egyptian Oases is famous for its clarity in the functional expression as clarified in the architectural expression of the functions, building in the mosque, the residence, and the shops by simple and simultaneous designs. In addition to the construction material, either the clay, red bricks or wood, using their natural colors. This clarity is also reflected in the functions of the public places in old cities. There different places are found such as parks and the market places where there is a clear distinction for the entrance of the place, and how the mosque's minaret constitutes a landmark, in addition to providing shaded places in the area.

\section{Deducing the principles for sustainable architectural design in Egyptian deserts}

\subsection{Conserving energy}

By using renewable energy resources in feeding the buildings with power by using solar energy, wind energy and energy generated by the hot wells that are abundant in the oasis.

\subsection{Adapting to climate}

1. The area of bare land, whether they are streets or courtyards to provide the largest spaces of shades and avoid sun exposed large areas.

2. Buildings closeness: buildings are aligned in bulks grouped together either horizontally or vertically to lessen the outer walls exposure to sun rays. In addition, the multiple turns in the streets and how narrow they are in proportion to the buildings' height help such high buildings provide more shade for the streets or even the opposite buildings, thus, alleviating the heat and break the direct sun rays.

3. Covering some parts of the streets using protruding construction parts along the street to form a "roof" to provide shade for the passengers and block the sun, thus, cooling the atmosphere.

4. Use the courtyard as an essential part of the houses to overcome the tough climatic conditions. The courtyard provides suitable light to the house units that overlook the yard. It also helps in creating air currents that air the building.

5. The buildings' facades are painted in a thick layer of clay or light lime stone colors to reflect sun rays. 


\subsection{Minimizing new resources}

Use the sustainable materials that are available in the surrounding environment, especially those materials that are effective heat isolators.

\section{Deducing the principles for sustainable urbanism in Egypt desert}

There are certain aspects that should be taken into consideration when attempting to develop the traditional Egyptian desert Cities. Most importantly, they must suit the surrounding environment concerning the natural and social aspects whether in relation to the climate or the nature of the terrain (mountains, oasis, and coasts). The process of planning must handle the heat and wear and tear issues by fixing the micro climate of the urban community. The most important basis and criteria for planning that must be taken into consideration to adapt the urban pattern to the external conditions are as follows.

\subsection{Interwoven patterns in its simplest forms}

Closely interwoven patterns of urbanization means that the buildings are closely linked along the streets that are narrow and zigzagged to ensure the facades protection from the direct sun rays and the hot wind, in addition to providing shade through the spaces. At the social level, the closely interwoven pattern has created close social relations, thus creating even smaller and simpler communities, which are less polluting and more sustained.

\subsection{Use interwoven pattern and airing them with courtyards}

Buildings which are blocked closely beside each other form one of the most important features of planning for a desert climate aiming at providing the largest amounts of shade, light, and natural ventilation, even to avoid the negative effects of the climate conditions. There is a direct relation between the amount of shade provided and how close the buildings are. Using courtyards and spaces between buildings to push air through them help create a cooler atmosphere than the hot one outside the buildings. This fact results in directing the residents' every day practices towards inside if the courtyards not outside the buildings where heat prevails.

\subsection{C-space ratios and volume}

In order to push the air current through the building, the spaces must be well directed as the biggest part of the space must be facing the air current to allow the air to flow inside of the space. The shape of the space directly controls the air movement, as it has proved that the central square space provides more protection against sand, disregarding the wind direction while the rectangular space provides good protection provided that the length of the space must not exceed three times its width, with the building's vertical axis directly perpendicular on the wind direction. 


\subsection{D-street planning and road networks}

The small number of streets and roads in the desert urban community leads to less traffic rates, directly effecting and lowering the sum of the sun rays and stabilizes the temperature inside the buildings. The architectural design that has spiral paths and zigzagged alleys receives less sun rays, less dusty and sandy winds and aids in stabilizing the climate be increasing the air speed, thus, providing suitable climate.

The proportion of building height to street width is considered a prim factor in providing shade, the angle of the sun rays hitting the streets is directly affected by the height as it helps in keeping the passengers in the shade almost all day long. The street depth differs according to the nature of the community, whether it is a humid or a dry desert community. A dry desert community requires a deep street to reach a stabilized climate, thus, the length factor to the width is larger than a prime number one. In the humid hot communities, it's better to attain shade by lowering the heights in order to move the hot humid air lying down the streets.

Proportionate the width of the streets is with their length. This fact helps in transforming the streets into channels for air flow, where it is always beneficial to design shorter streets in dry desert communities and longer ones in the humid desert communities.

\section{Conclusion}

In conclusion, sustainable design related to the surrounding environment is not a new concept. The integration between sustainable design elements and design concepts of traditional architecture and urbanism were tested and proven to be valid over long periods. This is realized through using construction materials and simple planning techniques that are derived from the local environment. Historically, the adaptation process occurred within the framework of sustainable development principles, for example constructing buildings using available materials and environment based techniques. These solutions were always effective and directly related to the surrounding environment and available resources.

\section{References}

[1] I.M. Afifi, "Populations in the dry desert areas of Egypt - an analytical study to assess the environmental performance of the models of the residential areas of heritage and developed in the Western Desert of Egypt", Master, Faculty of Engineering, Cairo University, 1985.

[2] A. Elgalad, "Ecological studies in geography and environment Egypt tourism", The World of Books, Second Edition, 2002.

[3] Y. Waziri, "The relationship between solar radiation and building design in North Africa", Institute of Research and Studies, Cairo University, 1997. 
[4] M. Al Badawe "Popular architecture in North Africa", The Construction Magazine, Issue 13, Riyadh, 1984.

[5] S.A. Alwakel, "Climate and architecture tropics", The World of Books 3rd Edition, 1989.

[6] A.O. Tntosh, "Natural ventilation in buildings" reporter of inheritance, reporter means the future of architecture in Libya, 2012.

[7] A. Khairuddin, "Environmental processors in Islamic city planning", Cairo, 1997.

[8] H. Fathi, "Architecture and the environment", Knowledge House, Cairo, 1977.

[9] O. Elnahass, "Desert Building", Anglo Egyptian Library, 1987.

[10] A. Fakhry, "Egyptian deserts (Elbaharea and Elfarafra oases)", Supreme Council of Antiquities Printing, Volume II, 1973, Print version 1999.

[11] B. Bayoumi, E. Abdullah, "Environmental control Imran Egyptian desert cities (entrance environmental planning and sustainable)", a research paper, Department of Urban Planning - College of Engineering, Al-Azhar University, 2012.

[12] A.M. Ali, "The impact of climatic conditions on the formation of the South Valley Building in Egypt (the city and beyond New Valley Western Sahara as an example)", Journal of Science and Technology, Volume 14, Issue, 2009.

[13] S.M. Alian, "Analytical study of the architectural perspective environmental of some historical buildings Dakhla Oasis (Bashandi Palace)", Institute of Environmental Studies and Research of Environmental Engineering, Master, 2003.

[14] M.S. Alzubaidi, B.R. Shaheen, "The principles of sustainability in traditional architecture according to the Islamic perspective”, Baghdad University, Faculty of Engineering, Architecture Department. 